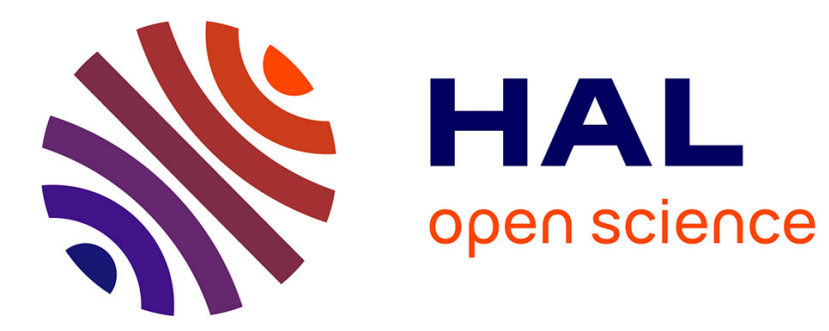

\title{
Ghrelin in type 2 diabetes mellitus and metabolic syndrome
}

Olavi Ukkola

\section{To cite this version:}

Olavi Ukkola. Ghrelin in type 2 diabetes mellitus and metabolic syndrome. Molecular and Cellular Endocrinology, 2011, 10.1016/j.mce.2011.02.009 . hal-00706316

\section{HAL Id: hal-00706316 https://hal.science/hal-00706316}

Submitted on 10 Jun 2012

HAL is a multi-disciplinary open access archive for the deposit and dissemination of scientific research documents, whether they are published or not. The documents may come from teaching and research institutions in France or abroad, or from public or private research centers.
L'archive ouverte pluridisciplinaire HAL, est destinée au dépôt et à la diffusion de documents scientifiques de niveau recherche, publiés ou non, émanant des établissements d'enseignement et de recherche français ou étrangers, des laboratoires publics ou privés. 


\section{Accepted Manuscript}

Title: Ghrelin in type 2 diabetes mellitus and metabolic syndrome

Author: Olavi Ukkola

PII:

S0303-7207(11)00117-1

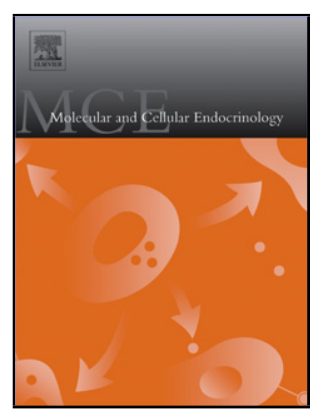

DOI: doi:10.1016/j.mce.2011.02.009

Reference: MCE 7772

To appear in: Molecular and Cellular Endocrinology

Received date: 29-11-2010

Revised date: $14-2-2011$

Accepted date: $14-2-2011$

Please cite this article as: Ukkola, O., Ghrelin in type 2 diabetes mellitus and metabolic syndrome, Molecular and Cellular Endocrinology (2010), doi:10.1016/j.mce.2011.02.009

This is a PDF file of an unedited manuscript that has been accepted for publication. As a service to our customers we are providing this early version of the manuscript. The manuscript will undergo copyediting, typesetting, and review of the resulting proof before it is published in its final form. Please note that during the production process errors may be discovered which could affect the content, and all legal disclaimers that apply to the journal pertain. 
Manuscript for "Molecular and Cellular Endocrinology"

\section{GHRELIN IN TYPE 2 DIABETES MELLITUS AND METABOLIC SYNDROME}

Olavi Ukkola MD, PhD

Department of Internal Medicine and Biocenter Oulu, University of Oulu, Oulu, Finland

Key words: ghrelin, insulin, diabetes

Address for correspondence:

Olavi Ukkola, M.D., Ph.D.

Assistant professor

Specialist in internal medicine and endocrinology

Department of Internal Medicine and Biocenter Oulu, University of Oulu,

Kajaanintie 50/P.O. Box 5000, Oulu, FIN-90014, Finland

Tel.: 08-315 4121, Fax. 08-3154139, E-mail: olavi.ukkola@oulu.fi 


\section{ABSTRACT}

The increasing prevalence of metabolic syndrome and the consequent cardiovascular diseases, like atherosclerotic diseases and Type 2 diabetes has stimulated an active search for novel risk factors. The hormones regulating energy balance are of special interest as potential risk factors for metabolic syndrome and Type 2 diabetes. Ghrelin is a peptide hormone from stomach with growth hormone releasing activity. It is also able to modify glucose and insulin metabolism, blood pressure levels, adipogenesis, and inflammatory processes in experimental conditions. Whether ghrelin has a role in the development metabolic syndrome and the associated diseases, is not known. This review will report the evidence for the role of ghrelin in the clustering of the components of the metabolic syndrome.

\section{GHRELIN IN METABOLIC SYNDROME}

Multiple metabolic aberrations, including obesity, insulin resistance, dyslipidemia, hypertension, impaired glucose tolerance, and other anomalies tend to occur jointly in the same subjects more frequently than expected by chance alone (Ferrannini, 1993). This clustering of several cardiovascular risk factors has been referred to as the metabolic syndrome (MS) (Reaven, 1988). The reasons for the joint occurrence of several abnormalities are still unclear even though the number of putative candidates is growing (Ukkola et al., 2001). A number of obesity-related peptide hormones have been identified and they have been recently suggested to play a role in the pathogenesis of MS (Matsuzawa et al., 1999). One such molecule is ghrelin, a blood-borne orexigenic signal from gut to brain (Kojima et al., 1999), with multiple hormonal, metabolic, and cardiovascular activities (Kojima et al., 2005). Low ghrelin concentrations have been associated with the components of the MS, like obesity (Tschöp et 
al., 2001), insulin resistance (Bacha and Arslanian, 2005; Pöykkö et al., 2003; Schöfl et al., 2002), and blood pressure (Fagerberg et al., 2003; Pöykkö et al., 2003). The negative association between ghrelin and waist circumference, a prerequisite for the MS, has also been reported (Fagerberg et al., 2003). In our cross-sectional study based on OPERA (Oulu Project Elucidating Risk of Atherosclerosis) cohort, the plasma ghrelin concentration was significantly correlated with several components of the MS and with metabolic cluster per se (Ukkola et al., 2006). OPERA project is a population-based, epidemiological study designed to address the risk factors and disease end-points of atherosclerotic cardiovascular diseases. Ghrelin levels decreased with an increase in number of metabolic abnormalities. Plasma ghrelin may therefore become a useful biomarker for the MS. Since adiposity influences all other features of the MS, low ghrelin in MS could reflect only the obesity state as has been suggested by a study by Langenberg et al. (2005). However, the associations of some of the features of the MS, like high-density lipoprotein (HDL) cholesterol and fasting blood glucose with plasma ghrelin levels, remained significant after adjustment for body mass index (BMI) (Ukkola et al., 2006) which is consistent with the notion that they are not entirely dependent on the amount of body fat.

Pathways leading from obesity to the manifestations of MS involve a number of metabolic risk factors (Sonnenberg et al., 2004). The resistance to insulin-stimulated glucose uptake is associated with multiple metabolic abnormalities. Consequently, insulin resistance has been suggested as a primary physiological defect underlying the MS (Reaven, 1988). The mechanisms behind insulin resistance are complex and have not been fully elucidated yet. Our earlier results on the same population suggested that low ghrelin is independently associated with fasting insulin concentrations and insulin resistance (Pöykkö et al., 2003). Because of cross-sectional nature of the current study it was not possible to conclude the cause-and-effect relationship between low ghrelin and insulin resistance and the MS. 
Ghrelin and leptin, two peptide hormones, interact with each other in the control of appetite (Nakazato et al., 2001). The interactions between leptin and ghrelin could also play a role in the pathogenesis of the clustering of metabolic abnormalities. Our earlier data confirm that in patients with the MS low plasma ghrelin levels act as a physiological counterpart to high leptin and that these changes are linked to the insulin resistance (Ukkola et al., 2008) (Figure). The latter notion was supported by the observed association of low ghrelin with insulin resistance only among the subjects with the highest leptin levels, that is, in subjects who probably have the highest level of leptin resistance. A large proportion of the subjects with the MS develop Type 2 diabetes in later stages of their life. In this study low ghrelin was a statistically significant independent predictor of Type 2 diabetes only among the subjects belonging to the highest leptin quartile. Thus, leptin seems to be the major determinant of ghrelin effects on progression of metabolic syndrome. We recognize that diabetic subjects in this study were a small subgroup and strong conclusions can not be made based on this material. Undoubtedly the development of MS and Type 2 diabetes involve multiple and interactive effects of genetic, hormonal and environmental factors where interaction between high leptin and low ghrelin seem to play a key role.

\section{GHRELIN IN TYPE 2 DIABETES MELLITUS}

The majority of the publications addressing the relationship between ghrelin and insulin resistance and/or diabetic states suggest that a correlation between ghrelin and insulin resistance and/or diabetes mellitus might exist. There is a growing body of evidence indicating a suppressive role of ghrelin in the release of insulin from the pancreatic islets. Recently Tong et al. (2010) suggested that circulating ghrelin suppresses glucose-stimulated insulin secretion and deteriorates glucose tolerance in healthy subjects. Their findings raised the possibility that 
endogenous ghrelin has a role in physiologic insulin secretion, and that ghrelin antagonists could improve beta-cell function (Tong et al., 2010). However, clinical relevance of these findings remains to be clarified and the study did not give conclusive answers to the question whether ghrelin has a physiological role in insulin secretion in humans (Meyer, 2010).

Ghrelin plasma concentrations were decreased in the healthy offspring of Type 2 diabetes subjects (Østergård et al., 2003) and the compensatory hyperinsulinaemia due to insulin resistance was associated with significantly reduced ghrelin concentrations. Pöykkö et al. (2003) showed that fasting plasma concentrations of total ghrelin were lower among subjects with Type 2 diabetes compared to those without Type 2 diabetes. The difference remained significant even when age, sex and BMI were taken into account in multivariable models. In addition, an inverse correlation between ghrelin and insulin concentrations as well as insulin sensitivity was observed. Low ghrelin concentrations were shown to associate independently with Type 2 diabetes and insulin resistance (Pöykkö et al., 2003). A strong inverse correlation between ghrelin concentrations and insulin resistance measured by homeostasis model of insulin resistance (HOMA-IR) and/or insulin concentrations has been observed also in other studies, for example among women with polycystic ovary syndrome (Schöfl et al., 2002) and in obese middle-aged subjects (McLaughlin et al., 2004). A recent study that aimed to clarify the relationships between total, acylated and des-acylated ghrelin molecules specifically with insulin resistance showed that these molecules might be involved in glucose and insulin metabolism in different ways. Total and des-acylated ghrelin were negatively associated with insulin resistance but instead, the correlation between acylated ghrelin and HOMA-IR was shown to be positive (Barazzoni et al., 2007).

Ghrelin may have a role in hepatic glucose metabolism (Gauna et al., 2005). It could also be speculated that low blood ghrelin levels might affect the growth hormone / insulin like growth factor -1 -axis which in turn might increase insulin resistance and lead eventually to the 
development of Type 2 diabetes mellitus. However, no causative link between ghrelin and the hyposomatotropism of obesity was observed previously (Lindeman et al., 2002). Therefore the theoretical link between low ghrelin, hyposomatotropism and pathogenesis of Type 2 diabetes remains highly speculative. A possible link between low ghrelin, insulin resistance and Type 2 diabetes might be the autonomous nervous system, although this hypothesis suggests no causal relationship between ghrelin and Type 2 diabetes. It has been shown that a higher ratio of sympathetic versus parasympathetic activity is strongly associated with metabolic abnormalities in humans (Licht et al., 2010). On the other hand, the autonomous nervous system has also been shown to be a factor regulating ghrelin concentrations (Hosoda and Kangawa, 2008). Therefore, it can be hypothesized, that dysregulation of the autonomic nervous system might cause a decrease in ghrelin levels as well as promoting the development of disturbances in glucose metabolism.

On the other hand, contradictory results with no association between ghrelin and pathologies of glucose metabolism have also been published. In healthy middle-aged men in a euglycaemic hyperinsulinemic clamp study, no associations between insulin sensitivity and ghrelin concentrations were observed (Fagerberg, 2003). We have studied whether total ghrelin levels have predictive value for the incidence of impaired glucose regulation (IGR) or Type 2 diabetes mellitus (Vartiainen et al., 2010). The subjects of this prospective follow-up study $(\mathrm{n}=201)$ belonged to a population-based cohort collected in Northern Finland. Oral glucose tolerance tests and measurements of fasting serum total ghrelin, lipids, blood pressure and body mass index were performed at the beginning and at the end of the study. The mean follow-up time was $5.1 \mathrm{yr}$. The subjects had normal glucose tolerance at the beginning of the study. Results suggested that fasting serum total ghrelin levels measured at one time point might not have predictive value for the development of abnormalities in glucose tolerance. Therefore, fasting serum ghrelin concentrations measured at one time point among normoglycaemic middle-aged subjects might not have a 
predictive value for the incidence of IGR or Type 2 diabetes mellitus. However, the results can not be regarded as conclusive, due to the small size of the study population. Studies in larger cohorts and with longer follow-up times are warranted to clarify the role of ghrelin in glucose and insulin metabolism. Our results are compatible with the results of Bennett et al. (2009) published recently. The design of this study, the follow-up times, as well as the subjects and methods used were very similar in the study of Bennett et al. compared to ours, with the exception that the study subjects were of different ethnic origins (Afro-Jamaicans $v s$ Caucasians). These two studies are the first to indicate that ghrelin might not have predictive value for the development of abnormalities in glucose tolerance.

\section{ASPECTS FOR FUTURE STUDIES}

Ghrelin is a pleiotropic hormone that might be involved in appetite control and energy metabolism. High hopes on studies concerning ghrelin and its receptor have been laid during the recent years, for potentially revealing new therapeutic tools for dysregulation of body weight and diabetes. Studies with larger study populations and longer follow-up times are needed to clarify the predictive value of ghrelin for the development of metabolic abnormalities and Type 2 diabetes. In addition, measuring acylated and des-acyl ghrelin separately in a similar study design might provide further information on the role of ghrelin in the regulation of glucose homeostasis. 


\section{REFERENCES}

Alberti, K.G., Zimmet, P., Shaw, J., 2005. IDF Epidemiology Task Force Consensus Group. The metabolic syndrome--a new worldwide definition. Lancet 366, 1059-1062.

Bacha, F., Arslanian, S.A., 2005. Ghrelin Suppression in Overweight Children: A Manifestation of Insulin Resistance? J. Clin. Endocrinol. Metab. 90, 2725-2730.

Barazzoni, R., Zanetti, M., Ferreira, C., Vinci, P., Pirulli, A., Mucci, M., Dore, F., Fonda, M., Ciocchi, B., Cattin, L., Guarnieri, G., 2007. Relationships between desacylated and acylated ghrelin and insulin sensitivity in the metabolic syndrome. J. Clin. Endocrinol. Metab. 92, 39353940.

Bennett, N.R., Boyne, M.S., Cooper, R.S., Royal-Thomas, T.Y., Bennett, F.I., Luke, A., Wilks, R.J., Forrester, T.E., 2009. Impact of adiponectin and ghrelin on incident glucose intolerance and on weight change. Clin. Endocrinol (Oxf). 70, 408-414.

Fagerberg, B., Hulten, L.M., Hulthe, J., 2003. Plasma ghrelin, body fat, insulin resistance, and smoking in clinically healthy men: the atherosclerosis and insulin resistance study. Metabolism. 52, 1460-1463.

Ferrannini, E., 1993. Syndrome X. Horm. Res. 39 (suppl 3), 107-111.

Gauna, C., Delhanty, P.J.D., Hofland, L.J., Janssen, J.A.M.J.L., Broglio, F., Ross, R.J.M., Ghigo, E., van der Lely, A.J.. 2005. Ghrelin stimulates, whereas des-octanoyl ghrelin inhibits, glucose output by primary hepatocytes. J. Clin. Endocrinol. Metab. 90, 1055-1060. 
Hosoda, H., Kangawa, K., 2008. The autonomic nervous system regulates gastric ghrelin secretion in rats. Regul. Pept. 146, 12-18.

Kojima, M., Hosoda, H., Date, Y., Nakazato, M., Matsuo, H., Kangawa, K., 1999. Ghrelin is a growth-hormone-releasing acylated peptide from stomach. Nature. 402, 656-60.

Kojima, M., Kangawa, K., 2005. Ghrelin: structure and function. Physiol. Rev. 85, 495-522.

Langenberg, C., Bergstrom, J., Laughlin, G.A., Barrett-Connor, E., 2005. Ghrelin and the Metabolic Syndrome in Older Adults. J. Clin. Endocrinol. Metab. 90, 6448-6453.

Lindeman, J.H.N., Pijl, H., Van Dielen, F.M.H., Lentjes, E.G.W.M., Van Leuven, C., Kooistra, T., 2002. Ghrelin and the hyposomatotropism of obesity. Obes. Res. 10, 1161-1166.

Licht, C.M., Vreeburg, S.A., van Reedt Dortland, A.K., Giltay, E.J., Hoogendijk, W.J., DeRijk, R.H., Vogelzangs, N., Zitman, F.G., de Geus, E.J., Penninx, B.W., 2010. Increased sympathetic and decreased parasympathetic activity rather than changes in hypothalamic-pituitary-adrenal axis activity is associated with metabolic abnormalities. J. Clin. Endocrinol. Metab. 95, 24582466.

Matsuzawa, Y., Funahashi, T., Nakamura, T., 1999. Molecular mechanism of metabolic syndrome X: contribution of adipocytokines adipocyte-derived bioactive substances. Ann. N. Y. Acad. Sci. 892, 146-154.

McLaughlin, T., Abbasi, F., Lamendola, C., Frayo, R.S., Cummings, D.E., 2004. Plasma ghrelin concentrations are decreased in insulin-resistant obese adults relative to equally obese insulin-sensitive controls. J. Clin. Endocrinol. Metab. 89, 1630-1635. 
Meyer, C., 2010. Final answer: ghrelin can suppress insulin secretion in humans, but is it clinically relevant? Diabetes. 59, 2726-2728.

Nakazato, M., Murakami, N., Date, Y., Kojima, M., Matsuo, H., Kangawa, K., Matsukura, S., 2001. A role for ghrelin in the central regulation of feeding. Nature. 409, 194-198.

Pöykkö, S.M., Kellokoski, E., Hörkkö, S., Kauma, H., Kesäniemi, Y.A., Ukkola, O., 2003. Low plasma ghrelin is associated with insulin resistance, hypertension, and the prevalence of type 2 diabetes. Diabetes. 52, 2546-2553.

Reaven, G.M., 1998. Role of insulin resistance in human disease. Diabetes. 37, 1595-1607.

Schöfl, C., Horn, R., Schill, T., Schlösser, H.W., Müller, M.J., Brabant, G., 2002. Circulating ghrelin levels in patients with polycystic ovary syndrome. J. Clin. Endocrinol. Metab. 87, 4607-4610.

Sonnenberg, G.E., Krakower, G.R., Kissebah, A.H., 2004. A novel pathway to the manifestations of metabolic syndrome. Obes. Res. 12, 180-186.

Tong, J., Prigeon, R.L., Davis, H.W., Bidlingmaier, M., Kahn, S.E., Cummings, D.E., Tschöp, M.H., D'Alessio, D., 2010. Ghrelin suppresses glucose-stimulated insulin secretion and deteriorates glucose tolerance in healthy humans. Diabetes. 59, 2145-2151.

Tschöp, M., Weyer, C., Tataranni, P.A., Devanarayan, V., Ravussin, E., Heiman, M.L., 2001. Circulating ghrelin levels are decreased in human obesity. Diabetes. 50, 707-709.

Ukkola, O., Bouchard, C., 2001. Clustering of metabolic abnormalities in obese individuals: the role of genetic factors. Ann. Med. 33, 79-90. 
Ukkola, O., Pöykkö, S., Päivänsalo, M., Kesaniemi, Y.A., 2008. Interactions between ghrelin, leptin and IGF-I affect metabolic syndrome and early atherosclerosis. Ann. Med. 40, 465-473.

Ukkola, O., Pöykkö, S.M., Kesäniemi, YA., 2006. Low plasma ghrelin concentration is an indicator of the metabolic syndrome. Ann. Med. 38, 274-279.

Vartiainen, J., Rajala, U., Jokelainen, J., Keinänen-Kiukaanniemi, S., Kesäniemi, Y.A., Ukkola, O., 2010. Serum ghrelin and the prediction of the development of impaired glucose regulation and type 2 diabetes in middle-aged subjects. J. Endocrinol. Invest. 33, 496-500.

Østergård, T., Hansen, T.K., Nyholm, B., Gravholt, C.H., Djurhuus, C.B., Hosoda, H., Kangawa, K., Schmitz, O., 2003. Circulating ghrelin concentrations are reduced in healthy offspring of Type 2 diabetic subjects, and are increased in women independent of a family history of Type 2 diabetes. Diabetologia. 46, 134-136. 
Figure legend

Adipose tissue - stomach link in the pathogenesis of MS.

Cluster of metabolic abnormalities that define metabolic syndrome according to the novel International Diabetes Federation definition (Alberti et al., 2005) are the following: Central obesity (defined as waist circumference $\geq 94 \mathrm{~cm}$ for Europid men and $\geq 80 \mathrm{~cm}$ for Europid women) plus any two of the following four factors: raised serum triglyceride(TG) level ( $\geq 1.7 \mathrm{mmol} / \mathrm{L}$ ) (or specific treatment for this lipid abnormality) reduced serum highdensity lipoprotein (HDL)-cholesterol level $(<1.03 \mathrm{mmol} / \mathrm{L}$ in males and $<1.29 \mathrm{mmol} / \mathrm{L}$ in females) (or specific treatment for these lipid abnormalities), raised blood pressure (systolic blood pressure $\geq 130 \mathrm{mmHg}$ or diastolic blood pressure $\geq 85 \mathrm{mmHg}$ ), or treatment of previously diagnosed hypertension, impaired fasting glycaemia (fasting plasma glucose $\geq$ $5.6 \mathrm{mmol} / \mathrm{L}$ ), or previously diagnosed type 2 diabetes.

High leptin and low ghrelin signals may synergize with each other to increase insulin resistance and the clustering of metabolic abnormalities and eventually Type 2 diabetes mellitus. 
Figure

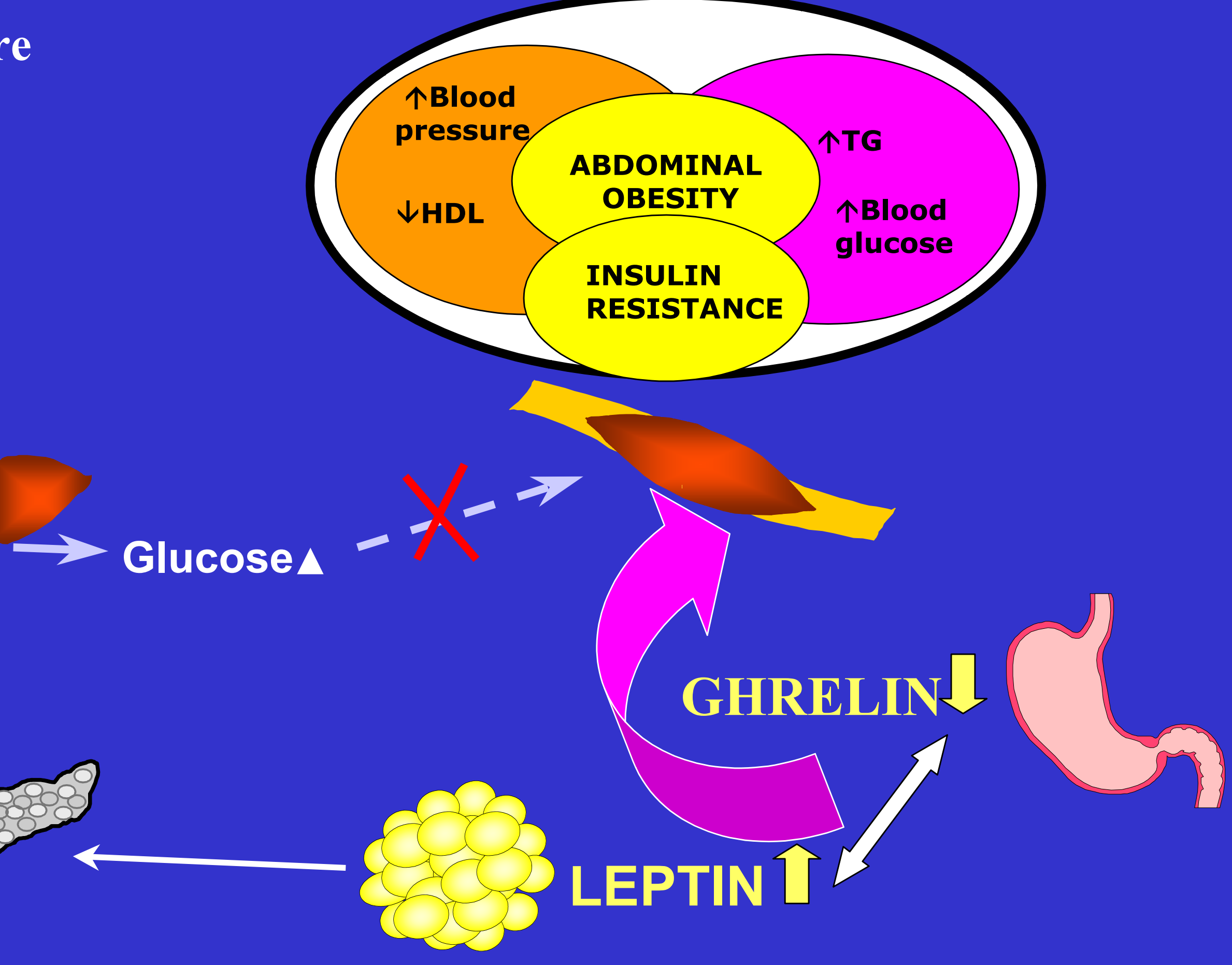

